\title{
IMPROVED FORMS OF STEADINESS TESTER AND TAPPING PLATE
}

\author{
BY KNIGHT DUNLAP
}

The Johrs Hopkins University

\section{Adjustable Steadiness Tester}

The form of steadiness tester illustrated in Fig. I has been in use in several departments of the Johns Hopkins University, and in other institutions, for several years, and has proved its value. The holes of graded sizes are arranged in a circle in a brass disc, which is placed in front of a second disc of the same size, having a single hole slightly larger than the largest hole in the first disc. The first disc turns on the short brass rod to which the second disc is fastened, so that any of the test holes can be brought over the single hole in the second disc. Two brass springs fastened to the second disc, and rubbing on the first disc, furnish friction sufficient to hold the first disc in any position, and also provide good electric contact between the two discs. By means of a thumbscrew on the rod, the pressure of the springs can be adjusted.

The rod carrying the two discs is held by a combination clamp on a vertical rod, so that the angle between the discsurface and the line of sight can be varied; the position of the single hole in the second disc can be varied; and the height of the discs can be varied. The cut shows the single hole at the bottom of the fixed disc. When used in this position, we find that adjusting the height so that the center of the disc is always at the height of the reactor's shoulder gives fair comparisons.

The instrument is shown a.8 connected with the 120-volt D. C. power line, with telephone receiver and two ro-watt lamps in series with stylus and plate. By using a lamp in each side of the circuit, no dangerous short-circuit can occur, 
although if the connections on the stylus and telephone receiver are not carefully covered, the psychologist or the reactor may receive a shock on touching the test-plate with the bare hand.

The telephone receiver is for most purposes as reliable as any available form of recording apparatus, in spite of the theoretical advantages of the latter. In cases where special study is to be made of the durations of touches, and where other considerations may be sacrificed to this, recording markers may be substituted for the telephone receiver, with appropriate change of current. For such work, a condenser must be used, of course. Dry cells may be used with the telephone receiver; but in that case, the durations of the touches can not be readily noted. 60 cycle, A. C. is even better than D. C. For most purposes, it is sufficient to count the number of touches in the standard time, and to note whether the reactor belongs to the type which readily follows instructions to move the stylus away from the brass immediately on making contact, or belongs to the type which tends to press the stylus against the brass.

The angular adjustment of the plate may be made once for all: we use it tilted upwards 15 degrees from the vertical. The vertical adjustment for each reactor, whether the tests are made in sitting or standing position, is of primary importance, if reactors are to be compared fairly. If it is desired to alternate between sitting and standing positions with a given reactor, two rings, one above and one below the clamp, may be set on the vertical rod in the proper positions, and the plates may then be slipped from the one position to the other without further measurement.

The rotation of the test-plate is also very important. By this means, each hole used is brought into exactly the same position for use, and hence in using a series of holes on one reactor, the arm and eye adjustment may be made identical for the several holes. In the older forms of plate, there are two holes which are adjacent in the series of sizes, but which 
lie, one at ane end of the top row, and the other at the other end of the bottom row. We have found that the change from one of these holes to the other introduces a decided 'step' in the numbers of touches in the holes in running through the series. Such disturbances are entirely avoided in our test-plate.

The test-plate is six inches in diameter, and has places for I5 holes arranged in a circle of two and three eighths inch radius. In the instruments used so far, only eleven of these holes have been put in, namely: holes of 8, 9, 10, I1, 12, 14, $16,18,20,22,24$, sixty-fourths of an inch diameter. This series seems excellently adapted to cover the requirements for work on children and adults; but any other series on either the inch or the millimeter scale may be put in.

The vertical rod which carries the plates is three fourths of an inch in diameter, and 30 inches long, and is mounted on a cast-iron base, designed for this instrument, which allows very convenient placing on any table.

\section{Double Tapping Plate}

In place of the usual single tapping plate, we are using a double plate, Fig. 2, and are requiring the reactor to strike the stylus alternately on the two plates. In this way, accurate records may be obtained by a make-and-break counter, such as the Ewald chronoscope. (Some Ewald chronoscopes will work accurately.) With the single plate, no form of counter yet devised will give accurate counts, and many serious errors may be made with a counter and plate which record fairly well for some reactors, and not for others. With the double plate, the necessary method of stroke gives more reliable contact, and slight oxidization of the plate is less important.

By using a definitely coördinated movement, we not only eliminate tremor-tapping, but also avoid some of the pseudopractice effects, due to changes of method in holding the stylus, in force of blow, and in force of grip of stylus: changes which come in suddenly in many cases with the single plate. 
The plates in this instrument are 3 inches square, separated by a bakelite block 1 inch wide, which rises $3 / 16$ ths of an inch above the surface of the plates. This block prevents the reactor from drawing the stylus across the plates. The plates are mounted on a cast-iron base, so heavy that it need not be fastened to the table. The base is hollow, and the condenser is to be placed under it, and connected to binding posts provided on the inside. The use of a condenser prevents the rapid deterioration of the plate surface. The Western Electric I microfarad condenser works well.

We are no longer able to undertake the manufacture of either of these instruments, and they will be supplied by Stoelting. 